\title{
The role of noninvasive methods in assessing airway inflammation and structural changes in asthma and COPD
}

\author{
K. Ahmad Dar ${ }^{1}$, M. Shahid², A. Mubeen², R. Bhargava1, \\ Z. Ahmad, I. Ahmad 3 , N. Islam4
}

ABSTRACT: The role of noninvasive methods in assessing airway inflammation and structural changes in asthma and COPD. K. Ahmad Dar, M. Shahid, A. Mubeen, R. Bhargava, Z. Ahmad, I. Ahmad, N. Islam.

Aim. The aim of our study was to assess the role of non-invasive methods in assessing airway inflammation and structural changes in asthma and COPD.

Methods. The study was conducted on patients attending outpatient and inpatient department of TB and Chest Diseases and Department of Pathology at our hospital from January 2006 to August 2007. 50 asthmatic and 46 COPD patients were selected. A detailed history and clinical examination, routine laboratory investigations, pulmonary function testing, Chest X-ray PA and lateral view, HRCT Thorax, biochemical and cellular analysis of sputum was carried out in all cases. Quality control and procedures of pulmomary function test were performed according to the European Respiratory Society guidelines.

Results. Bronchial wall thickening, bronchiectasis and air trapping correlated well with disease severity in asthmatics while all abnormal HRCT finding correlate well with disease severity in COPD patients. The levels of MMP-9 and TIMP-1 increased significantly with increasing disease severity in both asthmatic and COPD groups. The MMP-9/TIMP-1 ratio decreased with increasing disease severity in both groups. The major source of MMP-9 in human lungs is macrophages, neutrophils and eosinophils. Macrophages and neutrophils were also the source of TIMP-1.

Conclusion. Asthma and COPD are characterised by an imbalance between MMP-9 and TIMP-1. COPD patients showed a higher prevalence of HRCT findings which correlate with their lower MMP-1/TIMP-1 ratio than asthmatics supporting fact that the destruction and fibrosis of alveolar walls are more prominent in COPD. MMP-9/TIMP-1 ratio is associated with magnitude of HRCT findings in asthma and COPD and suggests that level of these markers reflect the extent of structural changes of airway.

Monaldi Arch Chest Dis 2012; 77: 1, 8-18.

Keywords: Airway remodelling, Asthma, COPD, HRCT, MMP-9, TIMP-1.

1 Department of TB and Chest Diseases, Jawaharlal Nehru Medical College AMU, Aligarh,

2 Department of Pathology, Jawaharlal Nehru Medical College AMU, Aligarh.

3 Department of Radiodiagnosis, Jawaharlal Nehru Medical College AMU, Aligarh,

4 Department of Biochemistry, Jawaharlal Nehru Medical College AMU, Aligarh, UP, India.

Correspondence: Dr. Mohammad Shahid, Department of Pathology, Jawaharlal Nehru Medical College, AMU, Aligarh, UP, India-202002; e-mail: shahidaftab@gmail.com

\section{Introduction}

Asthma and chronic obstructive pulmonary disease (COPD) share a condition of chronic inflammation of the airways, which is followed, to various extents and with different features, by a healing process that may lead to airway remodelling. Although the mechanisms of remodelling appear to be heterogeneous, and abnormal extracellular matrix $(\mathrm{ECM})$ degradation and deposition may play an important role in the development of structural alterations of the airways, contributing to airway stiffness and to irreversible airflow obstruction [1]. Such remodelling within the airway wall is to be attributed mainly to qualitative and quantitative changes of ECM proteins resulting from an imbalance between proteases and their inhibitors.

Inflammation in asthma and COPD is associated with increased production of active elastase, which can promote fibroblast migration through the ECM, as well as the degradation of elastic fibers $[2,3] \mathrm{ECM}$ homeostasis is also influenced by the balance between metalloproteinases (MMP) and their specific tissue-inhibitor metalloproteinases (TIMP), in such a way that increases of TIMP over MMP (or vice versa) can either lead to collagen deposition or degradation $[4,5]$.

With the advances in the field of lung imaging, it is now possible, to non-invasively quantify structural changes of the airways both in asthma and COPD [6, 7], making it possible to establish a close relationship between structural and functional abnormalities.

\section{Material and Methods}

The study was conducted on patients attending as outpatients or inpatients the TB and Chest 
Diseases and Department of pathology at Jawaharlal Nehru Medical College A.M.U., Aligarh from January 2006 to August 2007. 50 asthmatic and 46 COPD patients were selected. Bronchial asthma patients were selected according to criteria of American Thoracic society [8]. Asthma severity was assessed according to Global initiative for Asthma (GINA) Criteria. Current smokers, patients who had an upper or lower respiratory tract infection during the month preceding the test and patients who experienced a severe exacerbation of asthma resulting in hospitalisation were excluded from study. COPD patients with $\mathrm{FEV}_{1} / \mathrm{FVC} \leq 70 \%$ were selected as per Global Initiative for Chronic Obstructive Lung Disease (GOLD) guidelines 2004. Patients having the following conditions were excluded from the study; patients with a history of perennial allergic rhinitis, Patients with an improvement of $\mathrm{FEV}_{1}$ capacity of $>12 \%$ from baseline or an absolute value of $200 \mathrm{ml}$ following inhalation of $200 \mu \mathrm{g}$ salbutamol, patients with any upper or lower respiratory tract infection during the month preceding the test. The individual cases (50 Asthmatics and 46 COPD patients) were studied with emphasis on detailed history and clinical examination, Routine laboratory investigations, Pulmonary function testing, Chest X-ray PA and lateral view, HRCT Thorax, Biochemical and cellular analysis of sputum. Quality control and procedures of pulmonary function test were performed according to the European Respiratory Society guidelines $[10,11]$.

Computed tomography (CT) scans of the chest were performed with a spiral CT scanner in high-resolution mode according to the method of Mayo et al. [12]. In all subjects both end-inspiratory and end-expiratory HRCT scans were obtained using the following parameters $125 \mathrm{kV}, 310$ mAs, matrix size of $512 \times 512$, and a slice thickness of $1-1.25 \mathrm{~mm}$. A $20^{\circ}$ cranial inclination of the gantry was used to improve CT analysis at segmental and sub-segmental bronchi; the scanning time ranged from 1.5 to $3 \mathrm{sec}$. A window level of -600 Hounsfield units (HU) was chosen, with a width of 1,600 $\mathrm{HU}$, as generally recommended for the analysis of the bronchi and lung parenchyma $[12,13]$.

Sputum induction and processing were performed according to the methods of Fahy and colleagues [14] with slight modifications [2]. Patients were exposed to an aerosol of 3\% hypertonic saline solution, early in the morning, in a fasting condition for $20 \mathrm{~min}$. The subjects were encouraged to cough throughout the procedure, and regularly interrupted their inhalation of hypertonic saline in order to expectorate sputum into $50-\mathrm{ml}$ sterile ampoules. The aerosol was administered by an ultrasonic nebuliser (Fisoneb; Fisons Italchimici Spa, Rome, Italy), which generates particles with a median diameter of $2.5 \mu \mathrm{m}$ and has an output of $1 \mathrm{ml} / \mathrm{min}$. Sputum samples were immediately treated with $10 \%$ dithiotreitol (Sigma Chemical, St Louis, MO, USA) and centrifuged. The supernatants were immediately frozen for subsequent analysis. After fixation, the slides were stained by
Haematoxylin and Eosin Method and Papanicolau staining method. At least 200 cells per slide were counted and the differential cell counts were expressed as corrected percentage.

Determinations of the absolute value of MMP-9 and TIMP-1 in induced sputum were performed by ELISA (MMP-9-BIOTRAK ELISA and TIMP-1-BIOTRAK ELISA; Amersham International plc, Little Chalfont, UK), as previously described [5]. These assays measure the total amount of each respective protein (MMP-9 and TIMP-1), whether free or complexed to one another or to matrix. The limits of detection are 4-128 ngmL-1 for MMP-9 and 3.13-50 ngmL-1 for TIMP-1.

Results are given as mean \pm standard deviation. Chi-square test was used to analyse qualitative data. F-test was used to analyse quantitative data. For multiple comparisons, Bonferroni's correction was applied. P-values of $\leq 0.05$ were considered statistically significant.

\section{Results}

Out of the total 96 patients, 50 were suffering from asthma and the remaining 46 were having COPD. Out of the total 50 asthmatics, 23 (46\%) were males and 27 (54\%) were females. Out of the 46 COPD patients $34(73.91 \%)$ were males and 12 $(26.09 \%)$ were females. The mean duration of disease in asthmatics was $9.06 \pm 6.89$. Out of the 50 asthmatics $10(20 \%)$ cases belonged to intermittent and mild persistent group each and $15(30 \%)$ belonged to each moderate and severe persistent group. The mean duration of the disease in COPD patients was $17.52 \pm 8.44$ years. In COPD, most of the patients $(37 \%)$ belonged to moderate COPD, followed by $26.1 \%$ in very severe group.

The frequencies of abnormal CT findings and their severity in each severity group of asthmatics are shown in the (table 1). Bronchial wall thickening was the most prominent abnormal of the HRCT findings and increases in frequency and severity as the severity of the disease increases. It was present in $12(80 \%)$ patients of moderate persistent asthma and $15(100 \%)$ patients of severe persistent asthma. Most of the HRCT abnormalities increase in frequency as the severity of asthma increases (figure 1), similarly the MMP-1 and TIMP-1 level increased from intermittent to severe persistent asthma. Only bronchial wall thickening, bronchiectasis and air trapping correlated well with disease severity in asthmatics $(\mathrm{p}<0.05)$ (figure 2). Other HRCT scan abnormalities did not differ among the disease severity groups in asthmatics $(\mathrm{p}>0.05)$.

The frequencies of abnormal HRCT findings and their severity in COPD are shown in (table 2). All abnormal HRCT findings increase in frequency as the disease progresses paralleling level of markers of remodelling MMP-1 and TIMP-1 in sputum. All the abnormal HRCT findings correlated well with disease severity in COPD patients $(p<0.05)$. Emphysema increases from $16.7 \%$ in mild COPD to $83.3 \%$ in very severe group. Centrilobular em- 


\begin{tabular}{|c|c|c|c|c|c|c|}
\hline & $\begin{array}{l}\text { Intermittent } \\
\quad(\mathrm{n}=10)\end{array}$ & $\begin{array}{l}\text { Mild persistent } \\
\qquad(\mathrm{n}=10)\end{array}$ & $\begin{array}{l}\text { Moderate persistent } \\
\qquad(\mathrm{n}=15)\end{array}$ & $\begin{array}{c}\text { Severe persistent } \\
\qquad(\mathrm{n}=15)\end{array}$ & $\begin{array}{c}\chi^{2} \text { value } \\
(\mathrm{df}=3)\end{array}$ & $P$ value \\
\hline Bronchial wall thickening & $4(40.0)$ & $7(70.0)$ & $12(80.0)$ & $15(100.0)$ & 12.171 & 0.007 \\
\hline Focal hyperlucency & $3(30.0)$ & $4(40.0)$ & $8(53.3)$ & $9(60.0)$ & 2.591 & 0.459 \\
\hline Thick linear opacity & $2(20.0)$ & $3(30.0)$ & $6(40.0)$ & $9(60.0)$ & 4.583 & 0.205 \\
\hline Centrilobular opacity & $1(10.0)$ & $3(30.0)$ & $6(40.0)$ & $8(53.3)$ & 5.150 & 0.161 \\
\hline Bronchiectasis & $0(0.0)$ & $2(20.0)$ & $3(20.0)$ & $8(53.3)$ & 9.806 & 0.020 \\
\hline Emphysema & $0(0.0)$ & $2(20.0)$ & $3(20.0)$ & $4(26.7)$ & 3.026 & 0.388 \\
\hline Mucoid impaction & $0(0.0)$ & $0(0.0)$ & $2(13.3)$ & $4(26.7)$ & 5.808 & 0.121 \\
\hline Air trapping & $2(20.0)$ & $3(30.0)$ & $10(66.7)$ & $12(80.0)$ & 12.024 & 0.007 \\
\hline
\end{tabular}

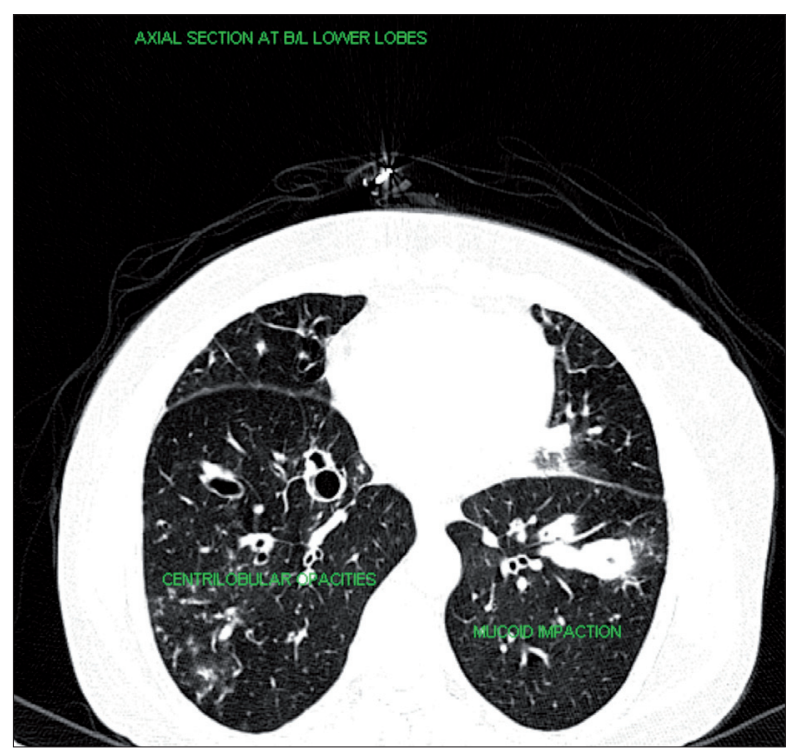

Fig. 1. - High-resolution CT scan through bilateral lower lobe shows dilated thick walled airways consistent with bronchiectasis with mucoid impaction in left lower lobe. Also shows small centrilobular nodules and branching linear opacities (tree in bud) in the right lower lobe.

physema was the most common form present (figure 3). There was no bronchiectasis in mild COPD. It increases in frequency from $5.9 \%$ in moderate COPD to $66.7 \%$ in very severe form of COPD. Cylindrical bronchiectasis was the most common form of bronchiectasis and right lower lobe was the most commonly involved lobe (figure 4).

All the physiological parameters of pulmonary function test such as FVC\%, FEVI/FVC\% and PEFR $(\mathrm{L} / \mathrm{sec})$ correlated well with the disease severity $(p<0.001)$ in asthmatic patients. There was a statistically significant difference between the severity groups in asthma $(p<0.001)$. Similarly all the values of pulmonary function test were statistically significant $(p<0.001)$ in COPD patients.

Except for squamous cells, the percentage of other cells differed significantly among the disease

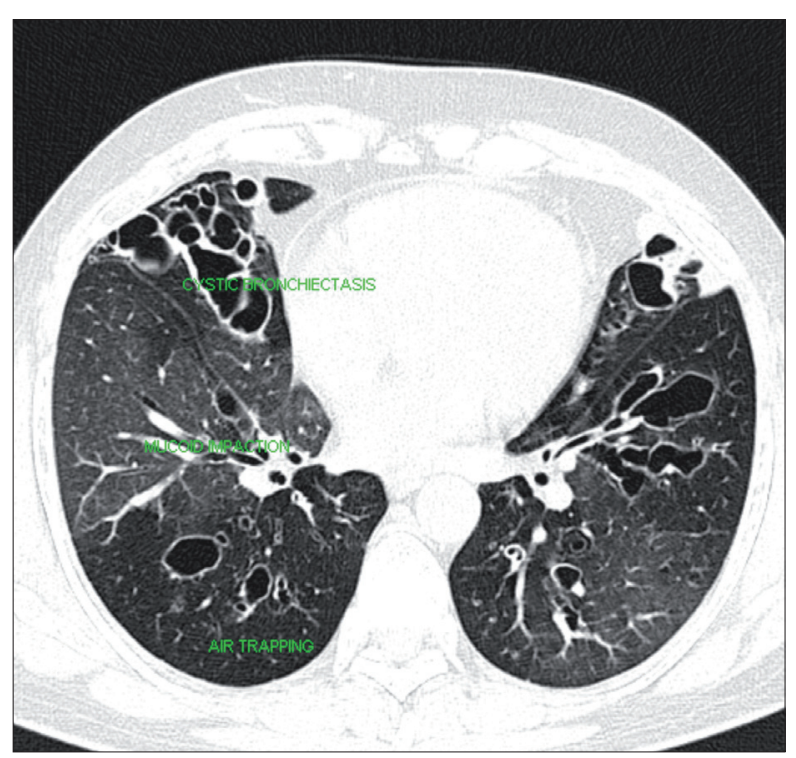

Fig. 2. - High-resolution CT scan through right middle, left lingular and bilateral lower lobe shows bilateral dilated thick walled airways with cluster of cysts within right middle lobe and lingular lobe typical of cystic bronchiectasis. Mosaic low-attenuation areas suggestive air trapping is seen in bilateral lower lobes.

severity groups in asthma in contrast the percentage of squamous cells was significantly lower in those with very severe disease compared to the other groups in COPD. As can be seen from (table 3), the percentage of macrophages in intermittent and severe persistent asthmatics differed significantly from the other groups while the percentage of macrophages decreased significantly with increasing severity of disease in COPD patients (table 4). The percentage of neutrophils differs significantly among different groups in asthma while the percentage of neutrophils was significantly higher in those with very severe COPD when compared to those with mild or moderate disease but did not differ significantly from those with severe disease. Except for intermittent $\mathrm{v} / \mathrm{s}$ moderate persistent \& mild $\mathrm{v} / \mathrm{s}$ severe persistent pairs, the percentage of 


\begin{tabular}{|c|c|c|c|c|c|c|}
\hline & $\begin{array}{l}\text { Mild } \\
(\mathrm{n}=6)\end{array}$ & $\begin{array}{c}\text { Moderate } \\
(\mathrm{n}=17)\end{array}$ & $\begin{array}{l}\text { Severe } \\
(\mathrm{n}=11)\end{array}$ & $\begin{array}{c}\text { Very Severe } \\
(\mathrm{n}=12)\end{array}$ & $\begin{array}{c}\chi^{2} \text { value } \\
(\mathrm{df}=3)\end{array}$ & $P$ value \\
\hline Bronchial wall thickening & $0(0.0)$ & $7(41.2)$ & $6(54.5)$ & $11(91.7)$ & 14.895 & 0.002 \\
\hline Focal hyperlucency & $1(16.7)$ & $7(41.2)$ & $8(72.7)$ & $11(91.7)$ & 12.798 & 0.005 \\
\hline Thick linear opacity & $2(33.3)$ & $5(29.4)$ & $8(72.7)$ & $10(83.3)$ & 10.890 & 0.012 \\
\hline Centrilobular opacity & $1(16.7)$ & $4(23.5)$ & $7(63.6)$ & $9(75.0)$ & 10.985 & 0.012 \\
\hline Bronchiectasis & $0(0.0)$ & $1(5.9)$ & $5(45.5)$ & $8(66.7)$ & 16.078 & 0.001 \\
\hline Emphysema & $1(16.7)$ & $2(11.8)$ & $7(63.6)$ & $10(83.3)$ & 18.288 & $<0.001$ \\
\hline Mucoid impaction & $0(0.0)$ & $2(11.8)$ & $5(45.5)$ & $9(75.0)$ & 16.279 & 0.001 \\
\hline Air trapping & $1(16.7)$ & $5(29.4)$ & $6(54.5)$ & $10(83.3)$ & 10.907 & 0.012 \\
\hline
\end{tabular}

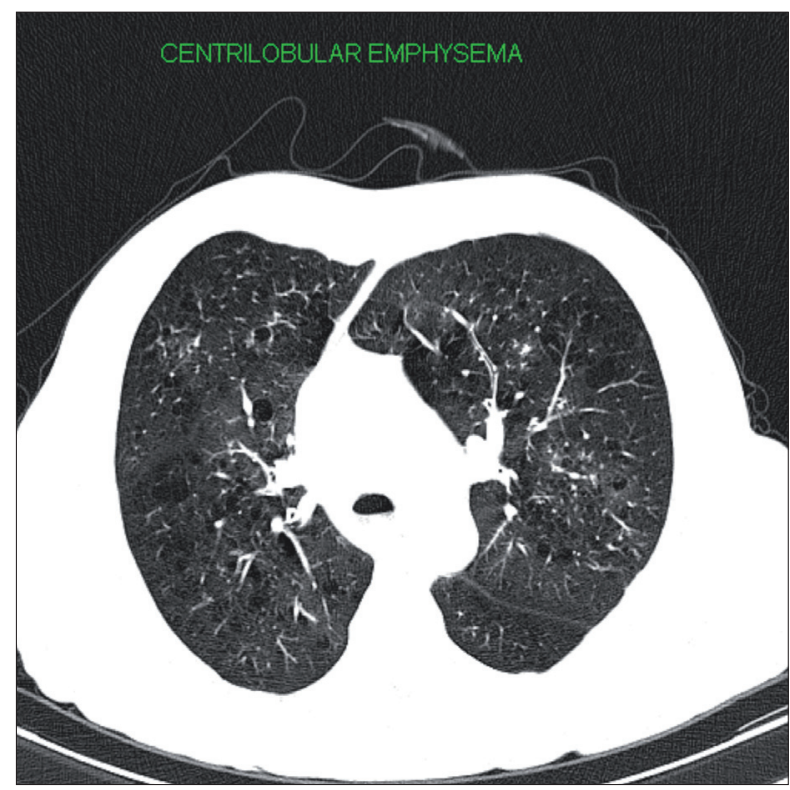

Fig. 3. - High-resolution CT scan through bilateral upper lobe shows non-uniformly distributed areas of low attenuation without visible walls with predominant centrilobular location in bilateral upper lobe typical of centrilobular emphysema.

eosinophils differed among the other pairs in asthma while the percentage of eosinophils did not differ among the COPD severity groups (figure 5). The percentage of lymphocytes in those with mild persistent asthma differed significantly from other groups in contrast the percentage of lymphocytes was highest in those with moderate COPD. The MMP-9 levels differed significantly among the disease severity groups in asthmatics. The TIMP-1 levels in those with severe persistent asthma were significantly higher than the other three groups. The MMP-9/TIMP-1 ratio was significantly higher in those with mild persistent asthma compared to those with severe persistent asthma. All the other pair wise differences for MMP-9/TIMP-1 ratio were insignificant (table 3). Applying bonferroni multiple comparison test $\mathrm{p}$ and correlations signifi-

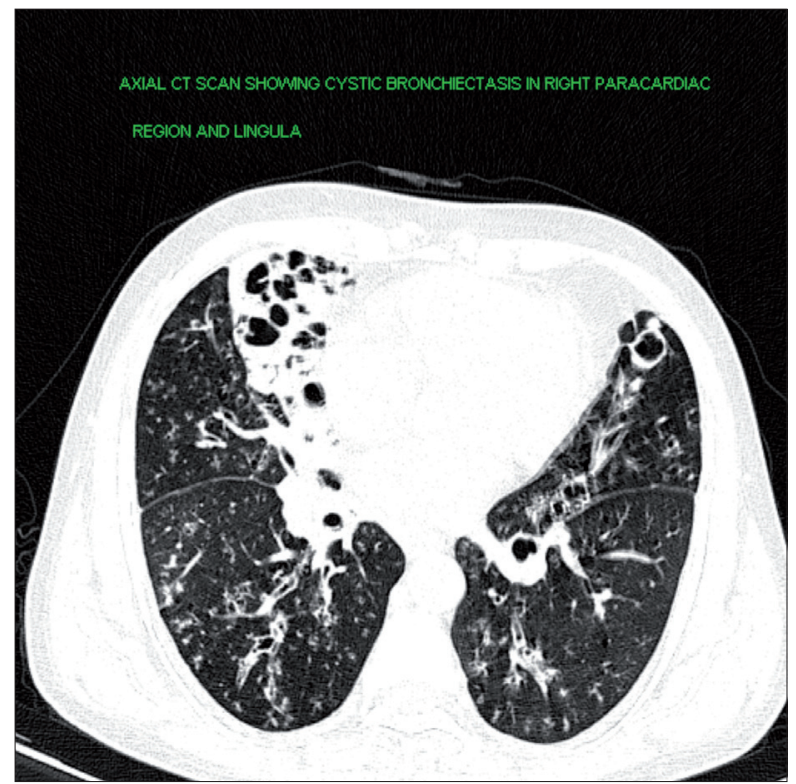

Fig. 4. - High-resolution CT scan through right middle, left lingular and bilateral lower lobe shows with cluster of thick wall cysts with few showing air-fluid level within right middle lobe and lingular lobe typical of cystic bronchiectasis. Adjacent middle lobe shows consolidation. Non tapering dilated thick walled tubular bronchi are seen in bilateral lower lobe consistent with cylindrical bronchiectasis.

cant negative correlation was observed between MMP-9 and TIMP-1 levels and macrophages \& lymphocytes $(\mathrm{p}<0.001)$. The levels of MMP-9 and TIMP-1 showed a significant positive correlation with neutrophils $(\mathrm{p}<0.001)$ and eosinophils $(p=0.001)$. The levels of MMP-9 and TIMP-1 increased significantly with increasing disease severity in COPD. The difference in the levels of both the mediators was however insignificant between the mild and moderate groups. The MMP-9/TIMP1 ratio decreased with increasing disease severity in COPD (table 4). The differences were however significant only between the mild $\mathrm{v} / \mathrm{s}$ very severe, moderate $\mathrm{v} / \mathrm{s}$ severe, and moderate $\mathrm{v} / \mathrm{s}$ very severe groups. A significant negative correlation was observed between MMP-9 \& TIMP-1 levels and macrophages, lymphocytes and eosinophils. The 


\begin{tabular}{|c|c|c|c|c|c|}
\hline CELLS & Severity of asthma & Mean & Standard Deviation & $\mathbf{F}$ & $P$ value \\
\hline \multirow{5}{*}{ Macrophages } & Intermittent & 64.520 & 3.1601 & \multirow{5}{*}{27.053} & \multirow{5}{*}{$<0.00$} \\
\hline & Mild persistent & 51.660 & 3.526 & & \\
\hline & Moderate persistent & 50.180 & 7.553 & & \\
\hline & Severe persistent & 34.420 & 12.592 & & \\
\hline & Total & 48.616 & 13.479 & & \\
\hline \multirow{5}{*}{ Neutrophils } & Intermittent & 30.920 & 3.123 & \multirow{5}{*}{22.988} & \multirow{5}{*}{$<0.001$} \\
\hline & Mild persistent & 41.490 & 4.719 & & \\
\hline & Moderate persistent & 48.780 & 7.426 & & \\
\hline & Severe persistent & 55.600 & 10.658 & & \\
\hline & Total & 45.796 & 11.627 & & \\
\hline \multirow{5}{*}{ Eosinophils } & Intermittent & 2.680 & 0.961 & \multirow{5}{*}{15.777} & \multirow{5}{*}{$<0.001$} \\
\hline & Mild persistent & 6.000 & 1.118 & & \\
\hline & Moderate persistent & 1.127 & 0.482 & & \\
\hline & Severe persistent & 5.287 & 3.504 & & \\
\hline & Total & 3.660 & 2.839 & & \\
\hline \multirow{5}{*}{ Lymphocytes } & Intermittent & 1.940 & 0.640 & \multirow{5}{*}{9.248} & \multirow{5}{*}{$<0.001$} \\
\hline & Mild persistent & 3.310 & 0.418 & & \\
\hline & Moderate persistent & 2.513 & 0.614 & & \\
\hline & Severe persistent & 2.513 & 0.614 & & \\
\hline & Total & 2.558 & 0.719 & & \\
\hline \multirow{5}{*}{ Squamous cells } & Intermittent & 16.690 & 3.276 & \multirow{5}{*}{2.576} & \multirow{5}{*}{0.065} \\
\hline & Mild persistent & 13.950 & 4.377 & & \\
\hline & Moderate persistent & 17.820 & 8.295 & & \\
\hline & Severe persistent & 10.853 & 9.360 & & \\
\hline & Total & 14.730 & 7.656 & & \\
\hline \multirow{5}{*}{ MMP-9 (ng/ml) } & Intermittent & 9.870 & 5.253 & \multirow{5}{*}{161.592} & \multirow{5}{*}{$<0.001$} \\
\hline & Mild persistent & 34.760 & 13.956 & & \\
\hline & Moderate persistent & 51.073 & 14.936 & & \\
\hline & Severe persistent & 147.293 & 24.621 & & \\
\hline & Total & 68.436 & 56.614 & & \\
\hline \multirow{5}{*}{ TIMP-1 (ng/ml) } & Intermittent & 63.090 & 43.136 & \multirow{5}{*}{127.303} & \multirow{5}{*}{$<0.001$} \\
\hline & Mild persistent & 83.510 & 18.248 & & \\
\hline & Moderate persistent & 147.780 & 45.097 & & \\
\hline & Severe persistent & 704.633 & 171.582 & & \\
\hline & Total & 285.044 & 295.636 & & \\
\hline \multirow{5}{*}{ MMP-9/TIMP-1 } & Intermittent & 0.29340 & 0.36881 & \multirow{5}{*}{3.222} & \multirow{5}{*}{0.031} \\
\hline & Mild persistent & 0.45040 & 0.22809 & & \\
\hline & Moderate persistent & 0.34567 & 0.02622 & & \\
\hline & Severe persistent & 0.21267 & 0.02249 & & \\
\hline & Total & 0.31626 & 0.20545 & & \\
\hline
\end{tabular}

levels of MMP-9 \& TIMP-1 showed a significant positive correlation with neutrophils $(\mathrm{p}<0.001)$.

Patients with COPD were significantly older than those with asthma. The percentage of squamous cells did not differ among asthmatics \& COPD patients. The percentage of neutrophils was significantly higher in COPD patients $(p<0.001)$. The percentage of other cells was significantly higher in asthmatics (table 5). The levels of MMP9 were not significantly different among the two groups. TIMP-1 levels showed a significantly higher mean value in COPD patients $(p<0.001)$. MMP9/TIMP-1 ratio was, however, reduced in COPD patients as compared to asthmatics $(p=0.028)$ (table $6)$. The most relevant correlations between
MMP9/TIMP-1 between different severity group of asthma and COPD has been demonstrated separately shown in table 7 and 8 .

Mucoid impaction \& emphysema were significantly more common in COPD patients, while bronchial wall thickening was more common in asthmatics. The frequency of other HRCT abnormalities did not differ among the two groups.

\section{Discussion}

The main results of this study is that a relationship exists between increased levels of cells and metalloproteinases in induced sputum and HRCT abnormalities in patients of bronchial asth- 


\begin{tabular}{|c|c|c|c|c|c|}
\hline CELLS & Severity of COPD & Mean & Standard Deviation & $\mathbf{F}$ & $P$ value \\
\hline \multirow{5}{*}{ Macrophages } & Mild & 52.950 & 4.281 & \multirow{5}{*}{128.190} & \multirow{5}{*}{$<0.001$} \\
\hline & Moderate & 41.059 & 7.276 & & \\
\hline & Severe & 19.509 & 1.667 & & \\
\hline & Very severe & 13.417 & 2.986 & & \\
\hline & Total & 30.246 & 15.500 & & \\
\hline \multirow{5}{*}{ Neutrophils } & Mild & 54.667 & 3.290 & \multirow{5}{*}{7.091} & \multirow{5}{*}{0.001} \\
\hline & Moderate & 56.741 & 10.637 & & \\
\hline & Severe & 62.691 & 3.417 & & \\
\hline & Very severe & 69.033 & 7.935 & & \\
\hline & Total & 61.100 & 9.462 & & \\
\hline \multirow{5}{*}{ Eosinophils } & Mild & 0.733 & 0.339 & \multirow{5}{*}{0.095} & \multirow{5}{*}{0.962} \\
\hline & Moderate & 0.800 & 0.326 & & \\
\hline & Severe & 0.745 & 0.339 & & \\
\hline & Very severe & 0.783 & 0.330 & & \\
\hline & Total & 0.774 & 0.321 & & \\
\hline \multirow{5}{*}{ Lymphocytes } & Mild & 2.183 & 0.440 & \multirow{5}{*}{6.985} & \multirow{5}{*}{0.001} \\
\hline & Moderate & 3.118 & 0.420 & & \\
\hline & Severe & 2.400 & 0.669 & & \\
\hline & Very severe & 2.408 & 0.644 & & \\
\hline & Total & 2.639 & 0.654 & & \\
\hline \multirow{5}{*}{ Squamous cells } & Mild & 17.717 & 2.934 & \multirow{5}{*}{7.547} & \multirow{5}{*}{$<0.001$} \\
\hline & Moderate & 18.047 & 7.353 & & \\
\hline & Severe & 16.300 & 8.030 & & \\
\hline & Very severe & 6.958 & 5.119 & & \\
\hline & Total & 14.693 & 7.935 & & \\
\hline \multirow{5}{*}{ MMP-9 (ng/ml) } & Mild & 37.417 & 10.397 & \multirow{5}{*}{96.717} & \multirow{5}{*}{$<0.001$} \\
\hline & Moderate & 52.906 & 15.783 & & \\
\hline & Severe & 85.691 & 20.472 & & \\
\hline & Very severe & 159.550 & 22.203 & & \\
\hline & Total & 86.546 & 49.849 & & \\
\hline \multirow{5}{*}{ TIMP-1 (ng/ml) } & Mild & 144.250 & 55.907 & \multirow{5}{*}{132.429} & \multirow{5}{*}{$<0.001$} \\
\hline & Moderate & 203.959 & 81.609 & & \\
\hline & Severe & 556.264 & 201.321 & & \\
\hline & Very severe & 1314.717 & 219.933 & & \\
\hline & Total & 570.180 & 496.258 & & \\
\hline \multirow{5}{*}{ MMP-9/TIMP-1 } & Mild & 0.32767 & 0.25315 & \multirow{5}{*}{5.144} & \multirow{5}{*}{0.004} \\
\hline & Moderate & 0.31294 & 0.20289 & & \\
\hline & Severe & 0.16273 & 0.03499 & & \\
\hline & Very severe & 0.12167 & 0.01171 & & \\
\hline & Total & 0.22904 & 0.17369 & & \\
\hline
\end{tabular}

ma and COPD. HRCT findings of asthma which correlate well with disease severity were bronchial wall thickening, bronchiectasis and air trapping $(p<0.05)$, while all abnormal HRCT findings correlated well with disease severity in COPD patients $(p<0.05)$. The difference is due to the fact that COPD is characterised by higher level of mediators of remodelling like MMP-1 and TIPM-1 in comparison to asthma. Mean Value MMP-1, TIPM-1 and MMP-1/TIMP-1 ratio for asthma was $68.436 \pm 56.614,285.044 \pm 295.636$ and $0.31626 \pm 0.20545$ while the values for COPD were $86.546 \pm 49.849$, $570.180 \pm 496.258$, and $0.22904 \pm 0.17369$ respectively. The results of our study showed that in sputum of asthmatics and COPD patients, both MMP-
9 and TIMP-1 are significantly increased. The mean value of MMP-9 for asthmatics was $68.436 \pm 56.614$. This varies from $9.870 \pm 5.253$ in the intermittent group to $147.293 \pm 24.621$ in severe persistent asthma $(p<0.001)$. The mean value of TIMP-1 for asthmatic patients was 285.044 295.636. It also increases as the severity of the disease with a statistically significant difference between the severity groups $(p<0.001)$. The MMP9/TIMP-1 was significantly higher in those with mild persistent asthma compared to those with severe persistent asthma. All the other pair-wise differences for MMP-9/TIMP-1 ratio were insignificant.

The mean value of MMP-9 and TIMP-1 for COPD patients were $86.546 \pm 49.849$ and $570.180 \pm 496.258$ 


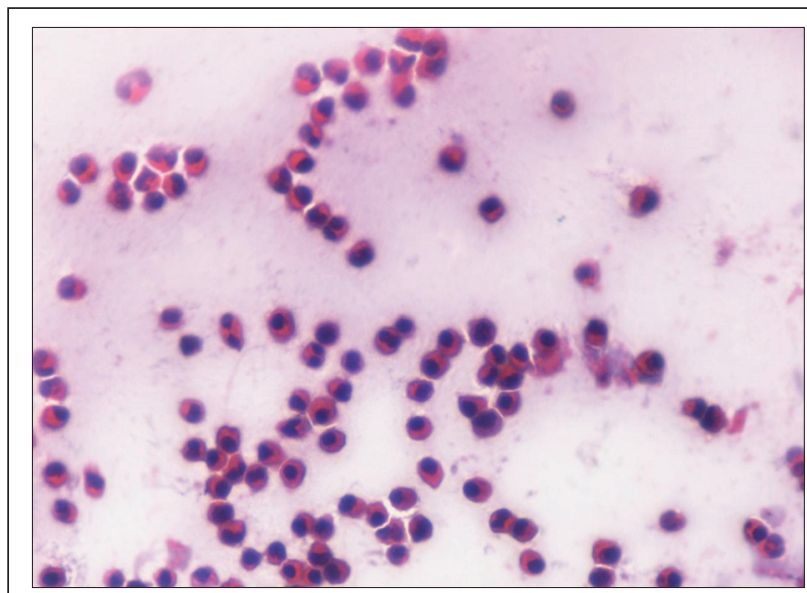

Fig. 5. - Sputum smear shows heavy eosinophilic cell infiltrate from a case of bronchial asthma (H \& E stain, 10x).

respectively. There was a statistically significant difference among the severity groups of COPD patients. The mean value of MMP-9/TIMP-1 ratio for COPD patients was $0.22904 \pm 0.17369$. There was a statistically significant difference among the various severity groups of COPD. The ratio decreased with increasing disease severity.

In our study, except for squamous cells $(p=0.065)$, the percentage of macrophages, neutrophils, eosinophils and lymphocytes differ significantly among the various severity groups $(\mathrm{p}<0.001)$ of asthma.

The percentage of eosinophils did not differ among the COPD severity groups. The percentage of macrophages decreased significantly with increasing severity of disease in COPD patients. The percentage of neutrophils was significantly higher in those with very severe COPD than those with mild or moderate disease but did not differ significantly from those with severe disease. The per-

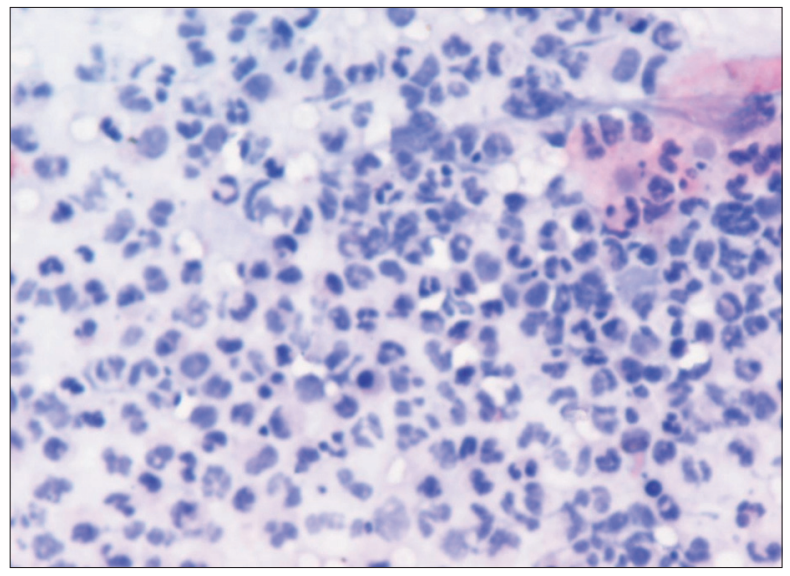

Fig. 6. - Sputum smear from COPD shows numerous polymorphonuclear leukocytes and background of macrophage and few squamous cells (PAP stain, 10x).

centage of lymphocytes was highest in those with moderate COPD.

Patients with COPD were significantly older than those with asthma. The percentage of squamous cells did not differ among asthmatics \& COPD patients. The percentage of neutrophils was significantly higher in COPD patients $(\mathrm{p}<0.001)$. The percentage of other cells was significantly higher in asthmatics. The levels of MMP-9 were not significantly different among the two groups. TIMP-1 levels showed a significantly higher mean value in COPD patients $(\mathrm{p}<0.001)$. MMP-9/TIMP1 ratio was, however, reduced in COPD patients as compared to asthmatics $(\mathrm{p}=0.028)$.

The results of our study are similar to previous studies done to assess airway remodelling in asthma and COPD. Vignola et al. [5] showed that MMP-9 and TIMP-1 concentrations were greater in sputum of patients with asthma and chronic bronchitis than in control subjects. The molar ratio

Table 5. - Baseline characteristics, cells and mediators in asthma

\begin{tabular}{llccc}
\hline Variable & N & Mean & Std. Deviation & p value \\
\hline Age (Years) & 50 & 33.66 & 17.05 & $<0.001$ \\
\hline Duration of Disease & 50 & 9.06 & 6.89 & $<0.001$ \\
\hline FEV $\mathbf{1} \%$ & 50 & 67.02 & 24.68 & $<0.001$ \\
\hline Macrophages & 50 & 48.616 & 13.479 & $<0.001$ \\
\hline Neutrophils & 50 & 45.796 & 11.627 & $<0.001$ \\
\hline Eosinophils & 50 & 3.660 & 2.839 & 0.019 \\
\hline Lymphocytes & 50 & 2.558 & 0.719 & $<0.001$ \\
\hline Squamous cells & 50 & 14.730 & 7.656 & 0.982 \\
\hline MMP-9 (ng/ml) & 50 & 68.436 & 56.614 & 0.101 \\
\hline TIMP-1 (ng/ml) & 50 & 285.044 & 295.636 & 0.001 \\
\hline MMP-9/TIMP-1 & 50 & 0.31626 & 0.20545 & 0.028 \\
\hline
\end{tabular}


Table 6. - Baseline characteristics, cells and mediators in COPD patients

\begin{tabular}{lllll}
\hline Variable & N & Mean & Std. Deviation & p value \\
\hline Age (years) & 46 & 61.72 & 11.21 & $<0.001$ \\
\hline Duration of Disease & 46 & 17.52 & 8.44 & $<0.001$ \\
\hline FEV $\%$ & 46 & 48.30 & 20.38 & $<0.001$ \\
\hline Macrophage & 46 & 30.246 & 15.500 & $<0.001$ \\
\hline Neutrophils & 46 & 61.100 & 9.462 & $<0.001$ \\
\hline Eosinophils & 46 & 2.639 & 0.654 & 0.019 \\
\hline Lymphocytes & 46 & 0.774 & 0.321 & $<0.001$ \\
\hline Squamous cell & 46 & 14.693 & 7.935 & 0.982 \\
\hline MMP-9 (ng/ml) & 46 & 86.546 & 49.849 & 0.101 \\
\hline TIMP-1 (ng/ml) & 46 & 570.180 & 496.258 & 0.001 \\
\hline MMP-9/TIMP-1 & 46 & 0.22904 & 0.17369 & 0.028 \\
\hline
\end{tabular}

between MMP-9 and TIMP-1 was lower in asthmatics and chronic bronchitis than in control subjects, and positively correlated with $\mathrm{FEV}_{1}$ values. In asthma, MMP-9 levels were significantly correlated with the number of macrophages and neutrophils. This study shows that airway inflammation in asthma and chronic bronchitis is associated with an imbalance between MMP-9 and TIMP-1 which may have a role in the pathogenesis of ECM remodelling and airflow obstruction.

Another study by Mattos et al. [15] showed similar results were assessing expression of MMP9 in asthma. Patients with severe asthma had increased levels and activity of sputum MMP-9 in their sputum compared with patients with mild asthma and normal subjects.

In 2002, Beeh et al. [16] conducted a study on the role of MMP-9, TIMP-1, and their molar ratio in patients with COPD, Idiopathic Pulmonary Fibrosis (IPF) and healthy subjects. Sputum MMP-9 levels were highest in COPD patients compared with IPF and controls $(\mathrm{P}<0.001$, both comparisons). Sputum TIMP-1 was also elevated in COPD and IPF patients compared with healthy controls $(\mathrm{P}<0.01$, both comparisons $)$. MMP9/TIMP-1 ratio was significantly higher in COPD patients than in those with IPF and controls $(P<0.01$, both comparisons). Sputum levels of TNF were similar in all three groups $(\mathrm{P}>0.2$, all comparisons). In this study, they showed that there was a positive correlation of sputum MMP-9 with sputum neutrophils in all subjects ( $\mathrm{rho}=0.68$, $P<0.001)$. There was a strong correlation of MMP9 and sputum TNF in COPD patients (rho $=0.76$, $P=0.004$ ), but not in IPF and healthy subjects.

Yildiz et al. [17] in 2003 conducted a study to demonstrate and compare the relative proportion of the cells in induced sputum samples in patients with asthma and COPD. Induced sputum total cell counts were higher in the COPD group as compared to the asthmatics, but the difference did not reach statistical significance $(\mathrm{P}>0.05)$. Sputum differential cell counts showed a predominance of neutrophils in COPD patients while eosinophils, lymphocytes and macrophages were more frequently seen in asthma patients. All these differences between the two groups were statistically significant.

The major sources of MMP-9 in human lung are macrophages [18] but this enzyme may also be released by eosinophils [19]. Our results suggest that in addition to macrophages and eosinophils, neutrophils are the major cell sources of MMP-9 in the airways. In the induced sputum of asthmatic and chronic bronchitis patients, Vignola et al. [5] had previously shown a significant correlation between the percentage of neutrophils and the concentrations of free elastase [2]. The percentage of neutrophils has also been found to be correlated with the content of MMP-9 in several lung diseases $[20,21]$. Thus, this study confirms previous evidence and suggests that neutrophils have the potential to destroy ECM and determine chronic injury of the lung in asthma and chronic bronchitis.

The increased concentrations of TIMP-1 found in asthma and chronic bronchitis can be the result of the effects of several mediators released during the development of airway inflammation in these diseases. Among these mediators, an important role may be played by transforming growth factor-b (TGF $\beta$ ) which is capable of increasing the production of TIMPs [22], and the expression of which is increased in the airways of asthmatic and chronic bronchitis patients [23]. This study also shows that macrophages and neutrophils are an important cellular source of TIMP-1, and points out 
Table 7. - Correlation between Asthma and MMP-9/TIMP-1

\begin{tabular}{llcccc}
\hline & Severity of Asthma & Mean & Standard deviation & F & P \\
\hline & Intermittent & 0.29340 & 0.36881 & & \\
MMP-9/TIMP-1 & Mild persistent & 0.45040 & 0.22809 & 3.222 & 0.031 \\
& Moderate persistent & 0.34567 & 0.02622 & & \\
& Severe persistent & 0.21267 & 0.02249 & $\mathbf{0 . 2 0 5 4 5}$ & \\
\hline
\end{tabular}

Table 8. - Correlation between COPD and MMP-9/TIMP-1

\begin{tabular}{llcccc}
\hline & Severity of COPD & Mean & Standard deviation & F & P \\
\hline & Mild & 0.32767 & 0.25315 & & \\
MMP-9/TIMP-1 & Moderate & 0.31294 & 0.20289 & 5.144 & 0.004 \\
& Severe & 0.16273 & 0.03499 & & \\
& Very severe & 0.12167 & 0.01171 & \\
\hline
\end{tabular}

the involvement of these cells in airway Remodelling in asthma and COPD. The results of the present study extend previous evidence obtained by Vignola et al, showing that airways macrophages isolated from bronchoalveolar lavage of asthmatic and chronic bronchitis patients release high concentrations of the profibrotic growth factor TGF-b and of fibronectin [24] and, therefore, lend support to the concept that macrophages and neutrophils actively participate in the Remodelling of the airways.

HRCT scan has been proposed as an additional tool to assess pulmonary changes in long-standing diseases, such as asthma and COPD [25, 26, 27]. Our study was also based on HRCT scan and we found that in asthmatic group bronchial wall thickening, bronchiectasis and air trapping correlated well with disease severity. In COPD patients all abnormal HRCT findings correlated well with the disease severity. Emphysema, bronchial wall thickening and bronchiectasis were the most frequently occurring abnormalities. HRCT scan has been previously used to quantify abnormalities of the airways due to airway remodelling and it has been found that the HRCT scan score correlated with the severity of asthma and airflow obstruction [28, 29]; conversely, conflicting results have been obtained on the relationship between HRCT-documented thickness of airway wall and hyper-responsiveness $[30,31]$ and, from these results, it can be derived that the issue of airway responsiveness is perhaps a more complex phenomenon than airway obstruction. In the current study, the HRCT outcome is represented by a final score that was obtained by counting the number of the observed lesions because it avoids the risk of underestimating the degree of pulmonary involvement. Indeed, this approach has the advantage of combining information from both airways and parenchyma. The observation of bronchiectasis in COPD patients is not controversial. Associations between emphysema and bronchiectasis are frequent and related to processes of traction and cicatrisation, reflecting a process of peri-bronchial fibrosis [32] and abnormal synthesis and degradation of ECM proteins, such as collagen and elastin. In the context of COPD, the current authors were also able to assess the parenchymal involvement, mostly emphysema.

An important finding of our study was the high prevalence of radiological bronchiectasis among patients diagnosed with COPD. CT scanning with a high resolution algorithm is now the investigation of choice to confirm a diagnosis of bronchiectasis [33] and, using generally accepted criteria $[33,34]$. We found that almost one third of the patients had bronchiectasis. It is likely that bronchiectasis is generally under diagnosed, particularly in smokers where cough and sputum production are assumed to be due to cigarette smoke and COPD [33]. In secondary care Currie et al. [35] found an incidence of bronchiectasis of $70 \%$ by bronchography and Smith et al. [36] reported an incidence of $68 \%$ by HRCT scanning.

Focal hyperlucency was found in $48 \%$ of asthmatic patients and $58.6 \%$ of COPD patients. These results were in accordance with Harmanci et al. [37] in which it was found that focal hyperlucency was seen in $37 \%$ of the asthmatics, which is not different from that observed in COPD patients $(33.3 \%)$.

Small centrilobular opacities were found in $36 \%$ of asthmatic patients and $45.6 \%$ of COPD patients. Similarly Harmanci et al. [37], found that small centrilobular opacities, caused by peribronchiolar inflammation and muscular hypertrophy, are found in $24.2 \%$ of the asthmatics, a prevalence that is not different from that in COPD patients (40.7\%). Lynch et al. [37] reported a proportion of $10 \%$ whereas Grenier et al. [38] reported that $21 \%$ of asthmatics have centrilobular prominence. We found that those features correlated with clinical severity and decreased $\mathrm{FEV}_{1}$ values. Focal hyper- 
lucency and small centrilobular opacities are known as small airway abnormalities. Therefore more recent studies have focused on the role for distal airways and suggest that more peripheral airways are also involved in asthma [39].

The present study concludes that ratio of MMP-9/TIMP-1 decrease with increasing severity in asthma and COPD and a close relationship exists between high-resolution computed tomography scan alterations and changes in the levels of markers of airway remodelling and these biological markers of remodelling might reflect the extent of structural changes occurring within the airways. The present study also provides evidence in support of the usefulness of a HRCT scan technique to assess structural alterations of the airways.

\section{References}

1. Vignola AM, Kips J, Bousquet J. Tissue remodelling as a feature of persistent asthma, J Allergy Immunol 2000; 105: 1014-1053.

2. Vignola AM, Bonanno A, Mirabella A, et al. Increased levels of elastase and 1-antitrysin in sputum of asthmatic patients. Am J Respir Crit Care Med 1998; 157: 505-511.

3. Fujita J, Nelson NL, Daughton MD, et al. Evaluation of elastase and antielastase balance in patients with chronic bronchitis and pulmonary emphysema. Am Rev Respir Dis 1990; 142: 57-62.

4. Murphy G, Docherty AJ. The matrix metalloproteinases and their inhibitors. Am J Respir Cell Mol Biol 1992; 7: 120-125.

5. Vignola AM, Riccobono L, Mirabella A, et al. Sputum metlloproteinase -9/tissue inhibitor of metalloproteinase-1 ratio correlates with airflow obstruction in asthma and chronic bronchitis. Am J Respir Crit Care Med 1998; 158: 1945-1950.

6. Park JW, Hond YK, Kim CW, Kim DK, Choe KO, Hong CS. High-resolution computed tomography in patients with bronchial asthma: correlation with clinical features, pulmonary functions and bronchial hyperresponsiveness. J Investig Allergol Clin Immunol 1997; 7: 1986-1992.

7. Baldi S, Miniati M, Bellina C, et al. Relationship between extent of pulmonary emphysema by high-resolution computed tomography and ling elastic recoil in patients with chronic obstructive pulmonary disease. Am Rev Respir Dis 2001; 164: 585-589.

8. American Thoracie Society. Definitions and classifications of chronic bronchitis, asthma and emphysema. Am Rev Respir Dis 1962; 85: 762-768.

9. WHO/NHLBI workshop report. Global strategy for asthma management and prevention. Bethesda, National Institutes of health, National Heart, Lung and Blood Institute, Revised 2002 (publication no. 02-3659).

10. Cotes JE, Chinn DJ, Quanjer PH, Roca J, Yernault JC. Standardization of the measurement of transfer factor (diffusing capacity). Report Working Party Standardization of Lung Function Tests, European Community for Steel and Coal. Official Statement of the European RespiratorySociety. Eur Respir J 1993; 16: 41-52.

11. Quanjer PH, Tammeling GJ, Cotes JE, et al. Symbols, abbreviations and units. Working Party Standardization of Lung Function Tests, European Community for Steel and Coal. Eur Respir J 1993; 6 (Suppl 16): 85-100.

12. Mayo JR, Webb WR, Gould R, et al. High-resolution CT of the lungs: an optimal approach. Radiology 1987; 163: 507-510.

13. Webb WR, Gamsu G, Wall SD, Cann CE, Protor E. CT of a bronchial phantom. Factors affecting appearance and size measurements. Invest Radiol 1984; 19: 394-398.
14. Fahy JV, Steiger DJ, Liu J, Basbaum CB, Finkbeiner WE, Boushey HA. Markers of mucus secretion and DNA levels in induced sputum from asthmatic and from healthy subjects. Am Rev Respir Dis 1993; 147: 1132-1137.

15. Mattos W, Lim S, Russell R, Jatakanon A, Chung KF, Barnes PJ. Matrix metalloproteinase-9 expression in asthma: effect of asthma severity, allergen challenge, and inhaled corticosteroids. Chest 2002; 122: 1543-52.

16. Beeh KM, Beier J, Kornmann O, Buhl R. Sputum matrix metalloproteinase-9, tissue inhibitor of metalloprotinease-1, and their molar ratio in patients with chronic obstructive pulmonary disease, idiopathic pulmonary fibrosis and healthy subjects. Respir Med 2003; 97: 634-9.

17. Yildiz F, Basyigit I, Boyaci H, Ilgazli A, Ozkara SK. Comparison of Induced Sputum Cell Counts in COPD and Asthma. Turkish Respiratory Journal 2003; 4: 43-46.

18. Campbell EJ, Cury JD, Shapiro SD, Goldberg GI, Welgus HG. Neutral proteinases of human mononuclear phagocytes: cellular differentiation markedly alters cell phenotype of serine proteinases, metalloproteinases, and tissue inhibitor of metalloproteinases. J Immunol 1991; 146: 1286-1293.

19. Ohno I, Ohtani H, Nitta Y, et al. Eosinophils as a source of matrix metalloproteinase-9 in asthmatic airway inflammation. Am J Respir Cell Mol Biol 1997; 16: 212-9.

20. Ricou B, Nicod L, Lacraz S, Welgus HG, Suter PM, Dayer JM. Matrix metalloproteinases and TIMP in acute respiratory distress syndrome. Am J Respir Crit Care Med 1996; 154: 346-352.

21. Delacourt C, Le-Bourgeois M, D'Ortho MP, et al. Imbalance between $95 \mathrm{kD}$ type IV collagenase and tissue inhibitor of metalloproteinases in sputum of patients with cystic fibrosis. Am J Respir Crit Care Med 1995; 152: 765-774.

22. Border W, Noble N. Transforming growth factor $b$ in tissue fibrosis. N Engl J Med 1994; 331: 1286-1292.

23. Vignola AM, Chanez P, Chiappara G, et al. Transforming growth factor-beta expression in mucosal biopsies in asthma and chronic bronchitis. Am J Respir Crit Care Med 1997; 156 (2 Pt 1): 591-9.

24. Vignola, Chanez AP, Chiappara G, et al. Release of transforming growth factor-b and fibronectin by alveolar macrophages in airway diseases. Clin Exp Immunol 1996; 106: 114-119.

25. Okazawa M, Muller N, McNamara A, Child S, Verburgt L, Pare P. Human airway narrowing measured using high resolution computed tomography. Am J Respir Crit Care Med 1996; 154: 1557-1562.

26. King G, Müller N, Paré P. Evaluation of airways in obstructive pulmonary disease using high-resolution computed tomography. Am J Respir Crit Care Med 1999; 159: 992-1004.

27. Nakano Y, Muller NL, King GG, et al. Quantitative assessment of airway remodelling using high-resolution CT. Chest 2002; 122 (6 Suppl): 271S-275S.

28. Paganin F, Seneterre E, Chanez P, et al. Computed tomography of the lungs in asthma: influence of disease severity and etiology. Am J Respir Crit Care Med 1996; 153: $110-114$

29. Niimi A, Matsumoto H, Amitani R, et al. Airway wall thickness in asthma assessed by computed tomography. Relation to clinical indices, Am J Respir Crit Care Med 2000; 162: 1518-1523.

30. Little S, Sproule M, Cowan M, et al. High resolution computed tomographic assessment of airway wall thickness in chronic asthma: reproducibility and relationship with lung function and severity. Thorax 2002; 257-253. 
31. Boulet L, Belanger M, Carrier G. Airway responsiveness and bronchial-wall thickness in asthma with or without fixed airflow obstruction. Am J Respir Crit Care Med 1995; 152: 865-71.

32. Loubeyre P, Paret M, Revel D, Wiesendanger T, Brune J. Thin-section CT detection of emphysema associated with bronchiectasis and correlation with pulmonary function tests. Chest 1996; 109: 360-365.

33. Cole PJ. Bronchiectasis. In: Brewis RAL, Corrin B, Geddes DM, Gibson GJ, eds. Respiratory medicine. London: WB Saunders, 1995; 1286.

34. Naidich DP, McCauley DI, Khouri, NF, et al. Computed tomography of bronchiectasis. $J$ Thorac Imaging 1986: 1: 94-103.

35. Currie DC, Cooke JC, Morgan AD, et al. Interpretation of bronchograms and chest radiographs in patients with chronic sputum production. Thorax 1986; 42: 278-84.
36. Smith J E, Jurriaans E, Diederich S, et al. Chronic sputum production; correlations between clinical features and findings on high resolution computed tomographic scanning of the chest. Thorax 1996; 51, 914-18.

37. Lynch DA, Newell JD, Tschomper BA, Cink TM, Newman LS, Bethel R. Uncomplicated asthma in adults: Comparison of CT appearance of the lungs in asthmatic and healty subjects. Radiology 1993; 188: 829-833.

38. Grenier P, Maurice F, Musset D, Menu Y, Nahum H. Bronchiectasis: Assessment with thin section CT. Radiology 1986; 161: 95-99.

39. Neeld DA, Goodman LR, Gurney JW, Greenberger PA, Fink JN. Computerized tomography in the evaluation of allergic bronchopulmonary aspergillosis. Am Rev Respir Dis 1990; 142: 1200-1205.

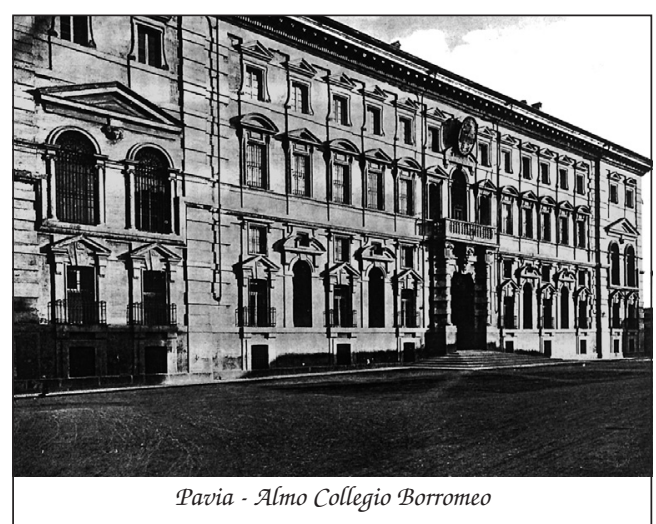

